\title{
PENGARUH LINGKUNGAN DAN TEMPAT TINGGAL PADA PENYAKIT ANAK UMUR 5 - 14 TAHUN DI KOTA BIAK TAHUN 2013
}

\author{
${ }^{1}$ Grace A. D. Kaidel \\ ${ }^{2}$ Sarah M. Warouw \\ ${ }^{2}$ Stefanus Gunawan
${ }^{1}$ Kandidat Skripsi Fakultas Kedokteran Universitas Sam Ratulangi Manado
${ }^{2}$ Bagian Ilmu Kesehatan Anak RSUP Prof. Dr. R. D. Kandou Manado

\begin{abstract}
Malaria is a disease of the symptoms of acute or chronic infection caused by Plasmodium, characterized by recurrent fever, chills, sweating, anemia and hepatosplenomegali. In Indonesia, malaria is still a major infectious disease, especially the East part. The most frequently found plasmodia are Plasmodium falciparum and Plasmodium malaria vivax. Risk factors are malnutrition, the state of the neighborhood around the bush, rice fields, ditches or gutters with puddle air. According to the Biak Health Department in January-December 2012 there were 3608 cases of malaria in 190 villages and the most commonly found was Plasmodium vivax. This was a descriptive observational study using cross-sectional study design. This study was done once in every neighborhood with diagnosed malaria patients. Samples were children aged 5-14 years who were diagnosed with malaria in public hospitals and health centers in Biak during October to December 2013, and the parents approved the form of a questionnaire study. Conclusion: In Biak, boys aged 5-7 years had the highest percentage of malaria. Environmental factors that affected might be the condition of house ventilation, not using repellent or mosquito nets, opened water reservoirs, puddle areas, bushes, and landfills around the houses.
\end{abstract}

Keywords: malaria, children, environment

\begin{abstract}
Abstrak: Malaria adalah penyakit infeksi akut atau kronis yang disebabkan oleh Plasmodium, ditandai dengan gejala demam rekuren, menggigil, berkeringat, anemia dan hepatosplenomegali. Di Indonesia, malaria masih merupakan penyakit infeksi utama khususnya dibagian Timur. Di kawasan Indonesia Timur plasmodia yang sering ditemukan ialah plasmodia falciparum dan vivax. Faktor risiko terkena malaria yaitu kekurangan gizi, keadaan lingkungan tempat tinggal disekitar semak belukar, persawahan, dan parit atau selokan dengan genangan air. Menurut Laporan Dinas Kesehatan Kota Biak penyakit malaria pada Januari-Desember tahun 2012 berjumlah 3608 kasus dengan jumlah 190 desa yang tertular. Malaria yang sering ditemukan yaitu plasmodium vivax. Penelitian ini bertujuan untuk mengetahui pengaruh lingkungan dan tempat tinggal pada penyakit malaria anak di Kota Biak, dengan rancangan potong lintang. Penelitian hanya dilakukan satu kali pada setiap lingkungan dan tempat tinggal pasien yang terdiagnosis malaria. Sampel ialah anak umur 5-14 tahun yang terdiagnosis malaria di RSU dan Puskesmas di Kota Biak selama bulan Oktober - Desember 2013 dan orang tua menyetujui penelitian berupa kuesioner. Simpulan: Di kota Biak, anak laki - laki berumur 5-7 tahun yang terbanyak terkena penyakit malaria. Hal ini mungkin disebabkan oleh faktor lingkungan antara lain ventilasi rumah yang tidak menggunakan kawat kasa, adanya genangan air dan terdapat semak- semak disekitar rumah, tidak memakai kelambu dan obat nyamuk saat tidur, tempat penampungan air yang tidak tertutup, dan tempat pembuangan sampah disekitar rumah.
\end{abstract}

Kata kunci: malaria, anak, lingkugan 
Malaria telah diketahui sejak zaman Yunani. Malaria diduga disebabkan oleh hukuman dewa, karena pada waktu itu ada wabah di sekitar kota Roma. Penyakit ini banyak ditemukan di daerah rawa yang mengeluarkan bau busuk ke sekitarnya, sehingga disebut "malaria" ( $\mathrm{mal}$ area = udara buruk = bad air). ${ }^{1}$

Di Indonesia, malaria masih merupakan penyakit infeksi utama khususnya dibagian Timur. Dikawasan Indonesia Timur Plasmodium yang sering ditemukan adalah Plasmodium falciparum dan Plasmodium vivax. ${ }^{2}$

Malaria adalah penyakit gejala infeksi akut atau kronis yang disebabkan oleh Plasmodium, ditandai dengan gejala demam rekuren, menggigil, berkeringat, anemia dan hepatosplenomegali. Di Indonesia, malaria tersebar diseluruh pulau dengan derajat endemisitas yang berbedabeda dan dapat berjangkit didaerah dengan ketinggian sampai 1800 meter diatas permukaan laut. Angka kejadian malaria di Jawa-Bali diukur dengan Annual Parasite Incidence (API), dan di luar Jawa-Bali diukur dengan Annual Malaria Incidence (AMI) malaria. ${ }^{3}$

Menurut Laporan Dinas Kesehatan Kota Biak penyakit malaria pada JanuariDesember tahun 2012 berjumlah 3608 kasus dengan jumlah 190 desa yang tertular. Malaria yang banyak ditemukan yaitu Plasmodium vivax. ${ }^{4}$

Tujuan dalam penelitian ini adalah mengetahui pengaruh lingkungan tempat tinggal dengan angka kejadian malaria pada anak di Kota Biak.

\section{METODE PENELITIAN}

Jenis penelitian ini observasional deskriptif dengan menggunakan rancangan penelitian studi potong lintang. Penelitian hanya dilakukan satu kali pada setiap lingkungan dan tempat tinggal pasien yang terdiagnosis malaria. Sampel yang diambil ialah anak umur 5-14 tahun yang terdiagnosis malaria di RSU dan puskesmas di Kota Biak selama bulan Oktober Desember 2013 dan orang tua menyetujui penelitian berupa kuesioner. Format

kuesioner untuk mendapatkan data dengan cara melihat pada data rekam medis di RSU dan Puskesmas terlebih dahulu, kemudian mengobservasi lingkungan tempat tinggal.

\section{HASIL PENELITIAN}

Karakteristik Responden

Dari hasil penelitian yang dilakukan di bagian Anak RSU Biak dan Puskesmas selama bulan Oktober - Desember 2013, ditemukan bahwa jumlah penderita malaria pada anak umur 5 - 14 tahun berjumlah 150 penderita.

Tabel 1. Distribusi seluruh penderita malaria berdasarkan bulan.

\begin{tabular}{lrr}
$\begin{array}{l}\text { Bulan Jumlah } \\
\text { penderita }\end{array}$ & \multicolumn{2}{c}{$\%$} \\
\hline Oktober 38 & 25,3 & \\
November & 55 & 36,7 \\
Desember 57 & 38 & \\
\hline Jumlah & 150 & 100 \\
\hline
\end{tabular}

Tabel 2. Distribusi penderita malaria berdasarkan perbedaan jenis kelamin.

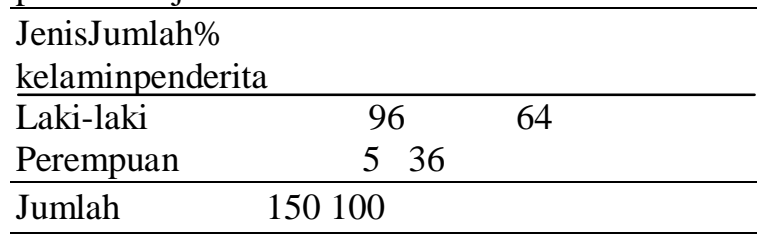

Tabel 3. Distribusi penderita malaria menurut umur.

Umur $\begin{aligned} & \text { Jumlah (tahun) } \\ & \text { penderita }\end{aligned}$

\begin{tabular}{llll}
$5-7$ & 76 & & 50.7 \\
\hline $8-10$ & 42 & 28 & \\
$11-14$ & 32 & & 21.3 \\
\hline Jumlah & 150 & 100 \\
\hline
\end{tabular}

Tabel 4.Distribusi penderita malaria berdasarkan daerah tempat tinggal.

\begin{tabular}{llc}
\hline $\begin{array}{l}\text { Daerah } \\
\text { tempat } \\
\text { tinggal }\end{array}$ & $\begin{array}{l}\text { Jumlah } \\
\text { penderita }\end{array}$ & $\%$ \\
\hline Pusat Kota & 50 & 33,3 \\
Pesisir Pantai & 60 & 40 \\
Pegunungan/Hutan & 40 & 26,7 \\
\hline Jumlah & 150 & 100 \\
\hline
\end{tabular}




\section{Karakteristik lingkungan dan tempat tinggal responden}

Pengumpulan data yang dilakukan dengan menggunakan kuesioner terhadap 150 sampel di RSU dan beberapa Puskesmas di Kabupaten Biak Numfor.

Berdasarkan hasil dari pengumpulan data tersebut, maka karakteristikresponden dapat dilihat pada tabel - tabel di bawah ini:

Tabel 5. Distribusi Responden berdasarkan bentuk bangunan rumah.

\begin{tabular}{lll}
\hline $\begin{array}{l}\text { Bentuk } \\
\text { bangunan } \\
\text { rumah }\end{array}$ & Jumlah & $\%$ \\
$\begin{array}{ll}\text { Tidak Permanen } \\
\text { Permanen }\end{array}$ & 7550 & \\
\hline Jumlah & 750 & 50 \\
\hline
\end{tabular}

Tabel 6. Distribusi Responden Berdasarkan Penggunaan Kawat Kasa pada Ventilasirumah responden.

\begin{tabular}{lcl}
\hline $\begin{array}{l}\text { Kawat } \\
\text { kasa }\end{array}$ & Jumlah & $\%$ \\
\hline Tidak & 77 & 51.3 \\
Ya & 7 & 48.76 \\
\hline Jumlah & 150 & 100 \\
\hline
\end{tabular}

Tabel 7. Distribusi Responden Berdasarkan Jarak Rumah yang satu dengan rumahlainnya.

\begin{tabular}{lll}
\hline $\begin{array}{l}\text { Jarak } \\
\text { rumah }\end{array}$ & Jumlah & $\%$ \\
\hline $\mathbf{5}$ Meter & 93 & 62 \\
$\geq 5$ Meter & 57 & 38 \\
\hline Jumlah & 150 & 100 \\
\hline
\end{tabular}

Tabel 8. Distribusi Responden Berdasarkan Genangan Air di sekitar Rumah responden.

\begin{tabular}{lcl}
\hline $\begin{array}{l}\text { Genangan } \\
\text { air }\end{array}$ & Jumlah \% \\
\hline Tidak & 58 & 38,7 \\
Ya & 92 & 61,3 \\
\hline Jumlah & 150 & 100 \\
\hline
\end{tabular}

Tabel 9. Distribusi responden berdasarkan semak - semak disekitar rumah responden.

\begin{tabular}{lcc}
\hline $\begin{array}{l}\text { Semak- } \\
\text { semak }\end{array}$ & Jumlah & $\%$ \\
\hline Tidak & 31 & 20,7 \\
Ya & 119 & 79,3 \\
\hline Jumlah & 150 & 100
\end{tabular}

Tabel 10. Distribusi responden berdasarkan pemakaian kelambu.

\begin{tabular}{lll}
\hline Kelambu & Jumlah & $\%$ \\
\hline Tidak & 93 & 62 \\
Ya & 57 & 38 \\
\hline Jumlah & 150 & 100 \\
\hline
\end{tabular}

Tabel 11. Distribusi Responden Berdasarkan Pemakaian Obat Nyamuk.

\begin{tabular}{lcc}
\hline $\begin{array}{l}\text { Obat } \\
\text { Nyamuk }\end{array}$ & Jumlah & $\%$ \\
\hline Tidak & 141 & 94 \\
Ya & 9 & 6 \\
\hline Jumlah & 150 & 100 \\
\hline
\end{tabular}

Tabel 12. Distribusi Responden Berdasarkan Tempat Penampungan Air.

\begin{tabular}{lll}
$\begin{array}{l}\text { Tempat } \\
\text { penampungan air } \\
\text { yang tertutup }\end{array}$ & Jumlah $\%$ \\
\hline Tidak & 107 & 71.3 \\
Ya & 43 & 28.7 \\
\hline Jumlah & 150 & 100 \\
\hline
\end{tabular}

Tabel 13. Distribusi responden berdasarkan tempat pembuangan sampahdisekitar rumah.

\begin{tabular}{lll}
\hline $\begin{array}{l}\text { Tempat } \\
\text { pembuangan } \\
\text { sampah }\end{array}$ & Jumlah & $\%$ \\
\hline Tidak & 42 & 28 \\
Ya & 108 & 72 \\
\hline Jumlah & 150 & 100 \\
\hline
\end{tabular}

\section{BAHASAN}

Berdasarkan penelitian dari 150 sampel yang diambil dari data rekam medis di RSU dan puskesmas pada bulan Oktober Desember 2013 yang paling banyak penderita malaria yaitu pada bulan desember $38 \%$, november $36.7 \%$ dan oktober $25.3 \%$.

Pada penelitian ini diperoleh hasil berdasarkan umur, penderita yang paling banyak menderita penyakit malaria yaitu umur 5-7 tahun 50.7\%, diikuti dengan umur 8-10 tahun $28 \%$ dan paling sedikit yaitu umur 11-14 tahun $21.3 \%$, sedangkanpada jenis kelamin, didapatkan laki-laki $64 \%$ dan perempuan $36 \%$. Beberapa Studi menunjukkan bahwa 
perbedaan prevalensi menurut umur dan jenis kelamin berkaitan dengan tingkat imunitas karena variasi keterpaparan gigitan nyamuk. ${ }^{5}$

Berdasarkan pemakaian kelambu diperoleh hasil tertinggi yaitu penderita tidak menggunakan kelambu saat tidur $62 \%$.

Observasi yang dilakukan oleh peneliti berdasarkan pemakaian obat nyamuk adalah penderita yang tidak menggunakan obat nyamuk lebih tinggi yaitu $94 \%$. Pada penelitian sebelumnya melaporkan makin rendah tingkat pemakaian obat nyamuk memberikan risiko terkena malaria lebih tinggi di bandingkan dengan yang memakai obat nyamuk. ${ }^{6}$

Pada daerah penelitian berdasarkan bentuk bangunan rumah di peroleh hasil sama yaitu bentuk bangunan rumah yang tidak permanen $50 \%$ dan permanen $50 \%$. Pada penelitian sebelumnya dilaporkan bahwa semakin tidak permanen suatu rumah maka semakin besar risiko terinfeksi malaria. $^{7}$

Berdasarkan hasil observasi disekitar lingkungan rumah tempat tinggallebih banyak memiliki semak - semak yaitu $79,3 \%$ sehingga intensitas infeksi malaria cukup tinggi. Penelitian sebelumnya melaporkan bahwa semak - semak merupakan tempat hinggap dan beristirahat dan berlindung nyamuk dari ancaman musuh. $^{8}$

Berdasarkan jenis parasit yang menginfeksi di peroleh hasil tertinggi yaitu plasmodium vivax 44\%. Diagnosis plasmodium vivax ditegakkan berdasarkan pemeriksaan laboratorik.

Salah satu faktor terjadinya malaria yaitu dengan ditemukannya genangan air disekitar rumah dan berdasarkan observasi yang dilakukan peneliti maka hasil tertinggi yang diperoleh yaitu $61,3 \%$ terdapat genangan air yang ditemukan di sekitar rumah penderita. Pada penelitian sebelumnya melaporkan bahwa genangan air disekitar rumah akan menjadi tempat untuk berkembang biak nyamuk Anopheles. ${ }^{7}$

Berdasarkan tempat penampungan air di peroleh hasil tertinggi $71,3 \%$ yaitu disetiap rumah penderita tidak menutup tempat penampungan air sehingga menjadi tempat perkembangbiakan nyamuk sehingga intensitas infeksi malaria tinggi. Nyamuk Anopheles hidup dan berkembangbiak serta meletakkan telurnya pada suatu wadah yang berisi air. Hal ini diperkuat dengan adanya penelitian sebelumnya yang melaporkan bahwa jentik - jentik nyamuk hidup ditempat yang lembab dan tempat yang berisi air.?

Berdasarkan pengamatan yang dilakukan oleh peneliti didapatkan hasil tertinggi yaitu $51,3 \%$ pada rumah penderita tidak menggunakan kawat kasa pada ventilasi rumah. Pada penelitian sebelumnya melaporkan rumah yang tidak menggunakan kawat kasa memiliki risiko tinggi terkena malaria. ${ }^{8}$

\section{SIMPULAN}

Hasil penelitian ini menyimpulkan bahwa terdapat anak laki-laki terbanyak yang berumur 5-7 tahun yang terkena penyakit malaria.Hal ini disebabkan oleh faktor-faktor yang memengaruhi lingkungan dan tempat tinggal pada penyakit malaria yaitu tidak menggunakan kawat kasa pada ventilasi rumah, jarak rumah satu dengan rumah lainnya $\leq 5$ meter, adanya genangan air dan semak-semak di sekitar rumah, tidak memakai kelambu dan obat nyamuk saat tidur, tempat penampungan air yang tidak tertutup, dan adanya tempat pembuangan sampah disekitar rumah.

\section{SARAN}

Bagi Petugas Kesehatan Kota Biak sebaiknya melakukan kegiatan surveilans kejadian malaria pada anak umur $5 \quad 14$ tahun dan secara rutin perlu meningkatkan kegiatan promosi kesehatan dalam penyuluhan guna mencegah terjadinya penularan penyakit malaria.

Bagi masyarakat harus lebih memperhatikan sanitasi di sekitar lingkungan dan tempat tinggal agar terhindar dari penyakit malaria. Untuk peneliti selanjutnya agar dapat mencari 
faktor lain seperti kebudayaan atau persepsi masyarakat yang menjadi penyebab kejadian malaria pada anak -anak yang tidak menjadi variabel resiko pada penelitian ini.

\section{DAFTAR PUSTAKA}

1. Staf Pengajar Departemen Parasitologi FKUI. Parasit malaria. Sutanto I, Ismid IS, Sjarifuddin PK, editors. Parasitologi kedokteran. 4 ed. Jakarta: Badan penerbit FKUI, 2008; p. 18990.

2. Harijanto PN, Agung N, Carta AG. Malaria dari Molekul ke Klinis. Jakarta: Penerbit Buku Kedokteran EGC, 2010.

3. Rampengan TH. Malaria pada anak. Harijanto P.N, Nugroho A, Gunawan AC, editors.Malaria.2009. Malaria dari Mokuler ke Klinis Edisi 2.
Jakarta: EGC; 2009. Pp. 156-19

4. Dinkes Biak Nufmor. Laporan Kasus Malaria. Biak: 2010

5. Rumbiak. Analisis Manajemen Lingkungan terhadap Kejadian Malaria di Kecamatan Biak Timur Kabupaten Biak Numfor Papua [Tesis]. Semarang: Universitas Diponegoro.

6. Masra F. Hubungan Tempat perindukan Nyamuk Dengan Kejadian Malaria Di Kecamatan Teluk Betung Barat Kota Bandar Lampung Tahun 2002. Jakarta: Universitas Indonesia, 2002.

7. Notosoedarmo S, Nurhadi, Martosupono M. Pengaruh Lingkungan Terhadap Kejadian Malaria di Kabupaten Mimika. 2010

8. Saputra E. Pengaruh Lingkungan Terhadap Nyamuk Anopheles Pada Proses Transmisi Malaria. Bengkulu, 2010. 